\title{
Sexual Function in Pregnant Women in the Public Health System
}

\author{
Cândice Cezimbra Miranda ${ }^{1}$, Amanda Vilaverde Perez ${ }^{2}$, Bruno Ribeiro Bossardi², \\ Luiza Cabreira Brust ${ }^{2}$, Fernanda Santos Grossi ${ }^{1}$, Edimárlei Gonsales Valério ${ }^{1,2,3}$, \\ Janete Vettorazzi ${ }^{1,2,3,4}$, Maria Celeste Osório Wender ${ }^{1,2,3,4}$
}

${ }^{1}$ PostgraduationProgram in Health Sciences: Gynecology and Obstetrics, Universidade Federal do Rio Grande do Sul (UFRGS). Rua Ramiro Barcelos, Santa Cecilia, Porto Alegre, RS, Brazil

${ }^{2}$ FAMED, UFRGS, Rua Ramiro Barcelos, Santa Cecilia, Porto Alegre, RS, Brazil

${ }^{3}$ Department of Gynecology and Obstetrics, Faculty of Medicine (FAMED), UFRGS, Rua Ramiro Barcelos, Santa Cecilia, Porto

Alegre, RS, Brazil

${ }^{4}$ Service of Obstetrics and Gynecology, Hospital de Clínicas de Porto Alegre (HCPA), Rua Ramiro Barcelos, Santa Cecília, Porto

Alegre, RS, Brazil

Email: ^jvettorazzi@hcpa.edu.br, edimarleigv@terra.com.br, amandavperez@gmail.com, bbossardi@hcpa.edu.br,

candice_cezimbra@yahoo.com.br, luizacbrust@gmail.com, fgrossi@hcpa.edu.br, mwender@hcpa.edu.br

How to cite this paper: Miranda, C.C., Perez, A.V., Bossardi, B.R., Brust, L.C., Grossi, F.S., Valério, E.G., Vettorazzi, J. and Wender, M.C.O. (2019) Sexual Function in Pregnant Women in the Public Health System. Open Journal of Obstetrics and Gynecology, 9, 764-774. https://doi.org/10.4236/ojog.2019.96076

Received: April 22, 2019

Accepted: May 28, 2019

Published: May 31, 2019

Copyright () 2019 by author(s) and Scientific Research Publishing Inc. This work is licensed under the Creative Commons Attribution International License (CC BY 4.0).

http://creativecommons.org/licenses/by/4.0/

\section{cc) (i) Open Access}

\begin{abstract}
Introduction: Pregnancy is a unique situation and involves changes in sexuality. The aim is to evaluate sexual function and satisfaction in pregnant women under prenatal care provided by the public health system. Method: Cross-sectional study with pregnant women receiving ambulatory care in the public health system in the Southern region of Brazil conducted between November 2014 and September 2015. Results: 283 pregnant women were studied. The mean age was $27.7 \pm 6.3$ years; $64 \%$ were white and $31.1 \%$ were nulliparous. In the total sample, $8.50 \%$ were in the first trimester of pregnancy, $37.4 \%$ were in the second trimester, and $54.1 \%$ were in the third trimester. The rate of global sexual dysfunction (score $<26$ points) was $55.5 \%$, following the application of The Female Sexual Function Index (FSFI). Sexual dysfunction was significantly more prevalent in the third trimester (62\%) compared to the first $(33.3 \%)$ and second $(50.9 \%)$ trimesters $(\mathrm{p}=0.015)$. There was a significant difference in all domains, except in the desired domain, according to the trimester. Pregnant women in the third trimester showed significantly lower scores compared to those in the first trimester in the domains with significance. Conclusion: The prevalence of sexual dysfunction among pregnant women in the public system was high. Knowing that more than $50 \%$ of the pregnant women presented sexual dysfunction, it is essential to approach sexuality during prenatal care involving the couple.
\end{abstract}




\section{Keywords}

Sexual Dysfunction, Pregnancy, Female Sexual Function Index, Sexuality, Sexual Function

\section{Introduction}

Sexuality is an important part of health and well being. Sexual function is fundamental in the personality of each human being and in the relationship of a couple. Female sexual dysfunction (FSD) is a frequent problem and quite often is underestimated in the community in general. It is defined as a disorder of the sexual desire, orgasm, arousal, or pain, which results in significant personal discomfort [1]. Sexuality is still a taboo subject for most women. The sexual behavior changes during pregnancy and the postpartum period, interfering with the quality of life and disturbing the union of the couple [2].

Numerous literatures show an association between pregnancy and sexual dysfunction [1] [2] [3] [4]. Sexual function is influenced by multiple factors, such as social, religious, neurological, organic and sociological [3]. The hormonal and emotional changes that occur during pregnancy can affect sexual activity, and one of the biggest fears is that sexual activity can cause harm to the fetus. [5]. Fatigue, anxiety and low back pain due to the typical postural alteration of gestation can also make the sexual relation unattractive to the woman [2].

Discussions on the female sexual function and sexual health often are deficient within the primary health care context [3]. Despite the importance of sexuality in the life of women, physicians are still reluctant to question them on this topic [4]. Difficulty in approaching the subject is even more intense during the gestational period.

Since sexuality can vary due to factors of pregnancy, as well as regional and environmental issues, we required an analysis of the sexual function of pregnant women attended in the public health system of Brazil.

\section{Methods}

A cross-sectional study was conducted among 283 pregnant women interviewed at the prenatal ambulatory of the public health system in the south of Brazil, from November 2014 to September 2015. The project was approved by the Hospital de Clínicas de Porto Alegre Ethics Committee 2014-0493.

The inclusion criteria were pregnant women of more than 18 years of age who were in prenatal care and agreed to participate in the study after signing an informed consent form. Women with neurological disorders and lack of cognition and understanding were excluded.

The participants were invited to answer a questionnaire about sociodemographic characteristics, health conditions and number of sexual intercourses in the past four weeks. Participants were also asked whether any advice on sexuality 
was given during the prenatal care, about years of schooling, and socioeconomic level. The marital status was stratified as with a partner and without a partner.

The Female Sexual Function Index (FSFI), a brief, specific, and multidimensional scale, was applied in a single interview with the patient. It was adapted to the Brazilian Portuguese, having a significant reliability and validity [5]. The FSFI is the first tool for evaluation of female sexual function that is validated in Portuguese and that fulfills all the requirements proposed for the international validation protocol [6]. The final scores can vary between 2 and 36, with higher scores indicating a better degree of sexual function [7]. Scores lower than 26.5 are considered as suffering from sexual dysfunction.

Data were analyzed using the Package for Social Sciences (SPSS) program, version 21.0. The quantitative variables were described by their means, standard deviation, and interquartile range. The qualitative variables had their absolute and relative frequencies. In order to compare the means, the $t$-student test for independent samples or the analysis of variance (ANOVA) complemented with a Tukey test was applied. For comparison of proportions, Pearson's chi-square and Fisher's exact test were applied. The associations between the continuous variables were evaluated by Pearson or Spearman correlation coefficient. The level of significance adopted was $5 \%(\mathrm{p} \leq 0.05)$.

\section{Results}

In this sample, 283 pregnant women in the public health system were interviewed; the average age was $27.7 \pm 6.3$ years. Of the total, 24 (8.50\%) were in the first trimester, 106 (37.44\%) in the second trimester, and $153(54.06 \%)$ in the third trimester. Most of these patients declared being white (63.6\%), having between 8 and 12 years of schooling (46.8\%), and earning a monthly income between one and five minimum wages $(78.1 \%)$. In this sample, the mean age at the beginning of sexual intercourse was $16.0 \pm 2.2$ years. Table 1 presents the characteristics of the total study population.

The rate of global sexual dysfunction (score $<26.5$ points) was $55.5 \%$. There was a significant difference between the trimesters relating to almost all domains, except the desired domain. Women in the third trimester of pregnancy had significantly lower scores than those in the first trimester in the domains. They included those women with a higher prevalence of sexual dysfunction (62.1\%), mainly when compared to women in the first trimester (33.3\%), according to what can be observed in Table 2. The remaining associations of the study's variables, such as years of schooling, number of abortions, number of pregnancies, and comorbidities (diabetes, systemic arterial hypertension, and psychiatric disorders), besides the use of medication, did not show a statistical difference when compared to the patients with and without sexual dysfunction (Table 3 and Table 4).

When comparing the FSFI domains according to income, women with an income above five minimum wages per month present significantly lower scores in 
Table 1. Sample characterization.

\begin{tabular}{|c|c|c|c|c|c|}
\hline Variables & $\begin{array}{l}\text { Total sample } \\
\quad(\mathrm{n}=283)\end{array}$ & $\begin{array}{c}1^{\text {st }} \text { trimester } \\
(\mathrm{n}=24)\end{array}$ & $\begin{array}{c}2^{\text {nd }} \text { trimester } \\
(\mathrm{n}=106)\end{array}$ & $\begin{array}{c}3^{\text {rd }} \text { trimester } \\
(\mathrm{n}=153)\end{array}$ & $\mathrm{p}$ \\
\hline Age (years) - mean $\pm S D$ & $27.7 \pm 6.3$ & $31.9 \pm 6.7^{\mathrm{b}}$ & $27.3 \pm 6.3^{\mathrm{a}}$ & $27.3 \pm 6.0^{\mathrm{a}}$ & 0.002 \\
\hline Skin color $-\mathrm{n}(\%)$ & & & & & 0.595 \\
\hline White & $180(63.6)$ & $17(70.8)$ & $67(63.2)$ & $96(62.7)$ & \\
\hline Black & $44(15.5)$ & $2(8.3)$ & $14(13.2)$ & $28(18.3)$ & \\
\hline Mixed & $59(20.8)$ & $5(20.8)$ & $25(23.6)$ & $29(19.0)$ & \\
\hline Marital status-n (\%) & & & & & 1.000 \\
\hline With partner & $280(98.9)$ & $24(100)$ & $105(90.1)$ & $151(98.7)$ & \\
\hline Without partner & $3(1.1)$ & $0(0.0)$ & $1(0.9)$ & $2(1.3)$ & \\
\hline Years of schooling $-\mathrm{n}(\%)$ & & & & & 0.117 \\
\hline$<8$ & $85(30.1)$ & $7(30.4)$ & $27(25.5)$ & $51(33.3)$ & \\
\hline $8-12$ & $132(46.8)$ & $7(30.4)$ & $58(54.7)$ & $67(43.8)$ & \\
\hline$>12$ & $65(23.0)$ & $9(39.1)$ & $21(19.8)$ & $35(22.9)$ & \\
\hline Income $-\mathrm{n}(\%)$ & & & & & 0.509 \\
\hline Up to $1 \mathrm{~m} . \mathrm{w}$. & 45 (15.9) & $6(25.0)$ & $19(17.9)$ & $20(13.1)$ & \\
\hline From 1 to 5 m.w. & $221(78.1)$ & $17(70.8)$ & $82(77.4)$ & $122(79.7)$ & \\
\hline$>5$ m.w. & $17(6.0)$ & $1(4.2)$ & $5(4.7)$ & $11(7.2)$ & \\
\hline $\begin{array}{l}\text { N. of pregnancies }-\mathrm{md} \\
(\mathrm{P} 25-\mathrm{P} 75)\end{array}$ & $2(1-3)$ & $2.5(1-4)$ & $2(1-3)$ & $2(1-3)$ & 0.680 \\
\hline Abortion-n (\%) & $57(20.1)$ & $7(29.2)$ & $18(17.0)$ & $32(20.9)$ & 0.381 \\
\hline $\mathrm{GA}$ (week)-mean $\pm \mathrm{SD}$ & $24.9 \pm 8.5$ & $10.1 \pm 1.6$ & $18.8 \pm 3.5$ & $31.5 \pm 4.5$ & $<0.001$ \\
\hline $\begin{array}{l}\text { Age at the beginning of sexual } \\
\text { life (years)-mean } \pm \text { SD }\end{array}$ & $16.0 \pm 2.2$ & $16.7 \pm 2.9$ & $15.9 \pm 2.2$ & $15.9 \pm 2.1$ & 0.220 \\
\hline $\begin{array}{l}\text { N. of partners in life }-\mathrm{md} \\
(\mathrm{P} 25-\mathrm{P} 75)\end{array}$ & $4(2-6)$ & $4(2.5-8)$ & $4(2-6)$ & $4(2-6)$ & 0.782 \\
\hline $\begin{array}{l}\text { N. of partners in the past } \\
\text { year-md (P25 - P75) }\end{array}$ & $1(1-1)$ & $1(1-1)$ & $1(1-1)$ & $1(1-1)$ & 0.120 \\
\hline $\begin{array}{l}\text { N. sexual intercourses in the } \\
\text { past month }- \text { md (P25 - P75) }\end{array}$ & $5(2-12)$ & $8(4-12)$ & $8(2-13)$ & $4(2-10)$ & 0.001 \\
\hline
\end{tabular}

$\mathrm{SD}=$ standard deviation .

Table 2. Sexual function in pregnant women (FSFI questionnaire).

\begin{tabular}{cccccc}
\hline Domains & $\begin{array}{c}\text { Total sample } \\
(\mathrm{n}=283)\end{array}$ & $\begin{array}{c}1^{\text {st }} \text { trimester } \\
(\mathrm{n}=24)\end{array}$ & $\begin{array}{c}2^{\text {nd }} \text { trimester } \\
(\mathrm{n}=106)\end{array}$ & $\begin{array}{c}3^{\text {rd }} \text { trimester } \\
(\mathrm{n}=153)\end{array}$ & $\mathrm{p}$ \\
\hline Desire & $3.62 \pm 1.21$ & $3.88 \pm 0.98$ & $3.59 \pm 1.25$ & $3.59 \pm 1.21$ & 0.552 \\
Arousal & $3.50 \pm 1.40$ & $4.32 \pm 0.80^{\mathrm{b}}$ & $3.69 \pm 1.22^{\mathrm{ab}}$ & $3.24 \pm 1.50^{\mathrm{a}}$ & $<0.001$ \\
Lubrication & $4.28 \pm 1.74$ & $5.17 \pm 0.94^{\mathrm{b}}$ & $4.41 \pm 1.61^{\mathrm{ab}}$ & $4.04 \pm 1.86^{\mathrm{a}}$ & 0.007 \\
Orgasm & $3.97 \pm 1.81$ & $4.80 \pm 1.37^{\mathrm{b}}$ & $4.18 \pm 1.67^{\mathrm{ab}}$ & $3.68 \pm 1.90^{\mathrm{a}}$ & 0.005 \\
Satisfaction & $4.13 \pm 1.55$ & $4.63 \pm 1.32^{\mathrm{b}}$ & $4.46 \pm 1.51^{\mathrm{ab}}$ & $3.82 \pm 1.53^{\mathrm{a}}$ & 0.001 \\
Pain & $3.92 \pm 1.82$ & $4.78 \pm 1.25^{\mathrm{b}}$ & $3.95 \pm 1.70^{\mathrm{ab}}$ & $3.75 \pm 1.93^{\mathrm{a}}$ & 0.033 \\
Total score & $23.4 \pm 7.62$ & $27.6 \pm 4.54^{\mathrm{b}}$ & $24.3 \pm 7.36^{\mathrm{ab}}$ & $22.1 \pm 7.89^{\mathrm{a}}$ & 0.001 \\
Sexual dysfunction $(<26$ points $)$ & $157(55.5)$ & $8(33.3)$ & $54(50.9)$ & $95(62.1)$ & 0.015 \\
\hline
\end{tabular}

${ }^{\mathrm{a}, \mathrm{b}}$ Similar letters do not differ by the Tukey test at $5 \%$ of significance. 
Table 3. Most frequent comorbidities cited by pregnant women.

\begin{tabular}{cccccc}
\hline Variables & $\begin{array}{c}\text { Total sample } \\
(\mathrm{n}=283)\end{array}$ & $1^{\text {st }}$ trimester & $2^{\text {nd }}$ trimester & $3^{\text {rd }}$ trimester & $\mathrm{p}$ \\
\hline Asthma & $10(3.5)$ & $1(4.2)$ & $3(2.8)$ & $6(4.0)$ & 0.883 \\
STDs & $3(1.1)$ & $0(0.0)$ & $1(0.9)$ & $2(1.3)$ & 0.835 \\
& & & & & \\
Gestational HAS & $38(13.4)$ & $9(37.5)$ & $12(11.3)$ & $17(11.1)$ & 0.001 \\
Diabetes & $60(21.2)$ & $2(8.3)$ & $22(20.8)$ & $36(23.5)$ & 0.236 \\
Hypothyroidism & $24(8.5)$ & $2(8.3)$ & $8(7.5)$ & $14(9.2)$ & 0.901 \\
Psychiatric disorders & $17(6.0)$ & $2(8.3)$ & $11(10.4)$ & $4(2.6)$ & 0.031 \\
Epilepsy & $3(1.1)$ & $1(4.2)$ & $1(0.9)$ & $1(0.7)$ & 0.292 \\
Twin pregnancy & $6(2.1)$ & 0 & $2(1.9)$ & $4(2.6)$ & 0.695 \\
\hline
\end{tabular}

Table 4. Medications used by pregnant women.

\begin{tabular}{cccccc}
\hline Variables & $\begin{array}{c}\text { Total sample } \\
(\mathrm{n}=283)\end{array}$ & $1^{\text {st }}$ trimester & $2^{\text {nd }}$ trimester & $3^{\text {rd }}$ trimester & $\mathrm{p}$ \\
\hline Ferrous sulphate & $78(27.6)$ & $1(4.2)$ & $24(22.6)$ & $53(34.6)$ & 0.003 \\
Calcium carbonate & $11(3.9)$ & 0 & $3(2.8)$ & $8(5.2)$ & 0.363 \\
AAS & $11(3.9)$ & 0 & $5(4.7)$ & $6(3.9)$ & 0.558 \\
Methyldopa & $26(9.2)$ & $10(41.7)$ & $7(6.6)$ & $9(5.9)$ & $<0.001$ \\
Metformin & $7(2.5)$ & $1(4.2)$ & $3(2.8)$ & $3(2.0)$ & 0.776 \\
Insulin & $3(1.1)$ & 0 & $1(0.9)$ & $2(1.3)$ & 0.835 \\
Levothyroxine & $15(5.3)$ & $1(4.2)$ & $5(4.7)$ & $9(5.9)$ & 0.888 \\
Fluoxetine & $12(4.2)$ & 0 & $8(7.5)$ & $4(2.6)$ & 0.086 \\
Folic acid & $12(4.2)$ & $4(16.7)$ & $6(5.7)$ & $2(1.3)$ & 0.002 \\
Carbamazepine & $4(1.4)$ & $1(4.2)$ & $2(1.9)$ & $1(0.7)$ & 0.348 \\
\hline
\end{tabular}

${ }^{*} \mathrm{p}<0.05$.

the domains of sexual arousal $(\mathrm{p}=0.011)$ and lubrication $(\mathrm{p}=0.027)$. There was also an association with the total score $(\mathrm{p}=0.043)$, with women with the highest income showing lower total scores $(19.0 \pm 9.8)$ when compared to those who earn less than one minimum wage per month $(23.3 \pm 7.1)$ and those who earn between one and five minimum wages per month $(23.8 \pm 7.5)$. When evaluating sexual dysfunction, the results regarding income were not statistically significant ( $\mathrm{p}=0.668$ ). The remaining associations of the study's variables, such as years of schooling, income, number of abortions, number of pregnancies, comorbidities didn't show statistical difference, when compared to the patients with and without sexual dysfunction.

\section{Discussion}

Pregnancy is a critical period in woman's life and, at this stage, sexual life can be affected by many factors. Physical and psychological changes have a significant impact on sexual activity. The most common sexual complaints in pregnancy are decreased in desire, on pleasure and in frequency of intercourse. Studies show that dysfunction increases with the progression of gestation [8]. Our study was not prospective, failing to assess whether FSFI scores decreased in the same patient throughout gestation. However, the prevalence of sexual dysfunction was higher among women in the third trimester than in the others. 
Decreased sexual activity during gestation may be related to woman's fatigue, nausea, lack of sexual interest, high number of children and myths and taboos about sexual behavior during pregnancy [9] [10] [11]. Partner's desire and fear of causing harm to the fetus also influence. Satisfaction with body image and body awareness are also important factors, although some studies show that couple's communication and partnership would be more relevant than body image variables [12].

We found a high prevalence of sexual dysfunction among pregnant women, mainly those in the third trimester, evidencing agreement with most of the studies published in different countries, using different evaluation tools in healthy pregnant women [5] [13]-[23]. In a Brazilian study published in 2015, the FSFI was applied to 207 pregnant women, showing sexual dysfunction in $35.7 \%$ of this population [24]. In another study published with 137 pregnant Brazilian women who answered the FSFI, sexual dysfunction was found in 61\% [21].

The literature shows that many couples are not prepared for the occurrence of sexual problems during pregnancy. This is due, in part, to insufficient information on the sexual life, as well as several factors that generally tend to decrease sexual function. There are still several controversies related to sexual activity and behavior during pregnancy, as well as the possible impact on pregnancy and the development of the sexual dysfunction [14]. There is no medical contraindication of sex in pregnancy, except under conditions like spontaneous rupture of membranes, threatened preterm labour or antepartum bleeding [25].

Iranian study has shown that unwanted pregnancy has an important impact on sexual function during pregnancy. Unwanted pregnancy causes stress, an important risk factor for sexual dysfunction. However, the study suggests that the most responsible factor for women avoiding sex during gestation is lack of adequate information about sex and concern about adverse outcomes in gestation [26]. It is well established that educational level has an important relation with sexual activity. Women with higher education have fewer sexual problems [27]. In our study there was no relationship between sexual dysfunction and educational level.

On the other hand, for some couples, pregnancy can become an incentive to search for new ways to please each other that do not necessarily lead to sexual intercourse [28]. This information is of utmost importance, as the population evaluated in our study has a median number of sexual intercourses that is significantly lower in the third trimester $(\mathrm{p}=0.001)$. Several studies have shown the existence of an important decrease of sexual activity and sexual interest in this trimester [2] [5] [14] [23] [29] [30].

It has been shown that women who had sexual dysfunction before pregnancy continued to have the problem during pregnancy and most of them had significant sexual dysfunction in the postpartum period [31] [32]. As our study was not prospective, this was not possible to evaluate. In the third trimester, there is a significant difference in sexual frequency between women with multiple pregnancies and the first pregnancy, with a decrease of intercourse in women in the 
first pregnancy, which does not occur with women with multiple pregnancies. It is believed that this is mainly related to the fear of the beginners in causing some damage to the fetus [8]. Sexual desire was reduced when compared to the same women in the first and third trimesters. The most common complaints were vaginal discomfort, increased fetal movement and low abdominal pain during the intercourse. Women's greatest concern was with fetal well-being, which is related to decreased sexual activity in the third trimester [1] [13] [25].

The negative perception of body image is another important factor to sexual dysfunction during pregnancy [25] [32] [33] [34] [35], although it may not be measured by FSFI. Non-acceptance of appearance is significant for refusing intercourse. Aslan [25] showed that the negative body image usually comes from the pregnant women themselves, and not from their partners.

One of the limitations of our study was the reduced number of pregnant women in the first trimester, reflecting their late arrival to the public health system, portraying the low awareness of the population about early initiation of prenatal care. We also found difficulties keeping the homogeneity of the sample relating to demographic variables that exist in the public health system of Brazil.

Evidence published in the literature shows that the specific changes in each trimester of pregnancy may significantly impact sexual behavior. Sexual function declines during pregnancy, particularly during the third trimester [36] [37]. This reduction is not resolved immediately after childbirth but can persist in the initial three to six months after birth, followed by a gradual and consistent recovery. The main factors that contribute to pregnant women's sexual life pertain to the physical and hormonal changes that lead to perception of a lack of attractiveness, as well as emotional and psychological changes, which can result in a loss of interest in sexual activity [19] [38]. In addition to the physical and hormonal changes, negative feelings about sexuality can lead to greater dissatisfaction in sexual and relationship life. Doubts and anxieties should be clarified by health professionals in order to minimize sexual problems during pregnancy and in the postpartum period [38].

A study conducted in Poland found that $68 \%$ of the young mothers studied were not informed during the prenatal care on sexual problems during pregnancy or, particularly, the possibility of obtaining satisfaction [28]. In our study, only 11 pregnant women ( $7 \%$ of the sample) replied positively to the question "During prenatal care, were you ever advised regarding your sexuality?" Health providers must be aware that a series of risk factors can contribute to sexual dysfunction during pregnancy [39]. Thus, more studies are necessary for a better evaluation of the pregnant women population regarding the social, cultural, and demographic contexts in which each woman is included.

\section{Conclusions}

This study has shown, in agreement with the most recent literature, the high prevalence of sexual dysfunction among pregnant women who are served by the 
Brazilian public health system, especially those who are in the third trimester. By using the FSFI, a standardized and validated questionnaire, the results of our research corroborate the findings of the literature worldwide.

Women with higher family income levels were more related to arousal and lubrication sexual dysfunction. Further studies are needed to correlate sexual dysfunction among pregnant women of different socioeconomic levels.

Both the literature and our work show an increase in sexual dysfunction during gestation and that many couples are not prepared for the sexual problems that arise in pregnancy. In part, this is due to insufficient information provided by physicians during prenatal care on sexual matters.

\section{Acknowledgements}

We would like to express our deepest gratitude to the participants for their time and patience throughout this study.

\section{Financial Disclosure}

The authors have no financial relationships relevant to this article to disclose.

\section{Conflicts of Interest}

The authors have no conflicts of interest to disclose.

\section{References}

[1] Raina, R., Pahlajani, G., Khan, S., Gupta, S., Agarwal, A. and Zippe, C.D. (2007) Female Sexual Dysfunction: Classification, Pathophysiology, and Management. Fertility and Sterilty, 88, 1273-1284. https://doi.org/10.1016/j.fertnstert.2007.09.012

[2] Aribi, L., Ben Houidi, A., Masmoudi, R., Chaabane, K., Guermazi, M. and Amami, O. (2012) Female Sexuality during Pregnancy and Postpartum: A Study of 80 Tunisian Women. Tunisie Medicale, 90, 873-877.

[3] Murtagh, J. (2010) Female Sexual Function, Dysfunction, and Pregnancy: Implications for Practice. Journal of Midwifery \& Women's Health, 55, 438-446. https://doi.org/10.1016/j.jmwh.2009.12.006

[4] Buster, J.E. (2013) Managing Female Sexual Dysfunction. Fertility and Sterilty, 100, 905-915. https://doi.org/10.1016/j.fertnstert.2013.08.026

[5] Leite, A., Moura, E., Campos, A., Mattar, R., Souza, E. and Camano, L. (2007) Validation of the Female Sexual Function Index in Brazilian Pregnant Women. Revista Brasileira de Ginecologia e Obstetrícia, 29, No. 8. https://doi.org/10.1590/S0100-72032007000800003

[6] do Rocio Cordeiro Thiel, R., Dambros, M., Palma, P.C.R., Thiel, M., Riccetto, C.L.Z. and de Fátima Ramos, M. (2008) Translation into Portuguese, Cross-National Adaptation and Validation of the Female Sexual Function Index. Revista Brasileira de Ginecologia e Obstetrícia, 30, 504-510. https://doi.org/10.1590/S0100-72032008001000005

[7] Khalesi, Z.B., Bokaie, M. and Attari, S.M. (2018) Effect of Pregnancy on Sexual Function of Couples. African Health Sciences, 18, 227-234.

https://doi.org/10.4314/ahs.v18i2.5 
[8] Leite, A.P.L., Campos, A.A.S., Dias, A.R.C., Amed, A.M., De Souza, E. and Camano, L. (2009) Prevalence of Sexual Dysfunction during Pregnancy. Revista da Associação Médica Brasileira, 55, 563-568. https://doi.org/10.1590/S0104-42302009000500020

[9] Jamali, S. and Mosalanejad, L. (2013) Sexual Dysfunction in Iranian Pregnant Women. Iranian Journal of Reproductive Medicine, 11, 479-486.

[10] Bartellas, E., Crane, J.M., Daley, M., Bennett, K.A. and Hutchens, D. (2000) Sexuality and Sexual Activity in Pregnancy. BJOG: An International Journal of Obstetrics \& Gynaecology, 107, 964-968. https://doi.org/10.1111/j.1471-0528.2000.tb10397.x

[11] Gokyildiz, S. and Beji, N.K. (2005) The Effects of Pregnancy on Sexual Life. Journal of Sex \& Marital Therapy, 31, 201-215. https://doi.org/10.1080/00926230590513410

[12] Radoš, S.N., Vraneš, H.S. and Šunjić, M. (2014) Limited Role of Body Satisfaction and Body Image Self-Consciousness in Sexual Frequency and Satisfaction in Pregnant Women. The Journal of Sex Research, 51, 532-541. https://doi.org/10.1080/00224499.2012.744954

[13] Prado, D.S., Lima, R.V. and de Lima, L.M.M.R. (2013) Impact of Pregnancy on Female Sexual Function. Revista Brasileira de Ginecologia e Obstetrícia, 35, 205-209. https://doi.org/10.1590/S0100-72032013000500003

[14] Gałązka, I., Drosdzol-Cop, A., Naworska, B., Czajkowska, M. and Skrzypulec-Plinta, V. (2015) Changes in the Sexual Function during Pregnancy. The Journal of Sexual Medicine, 12, 445-454. https://doi.org/10.1111/jsm.12747

[15] Tosun Güleroğlu, F. and Gördeles Beşer, N. (2014). Evaluation of Sexual Functions of the Pregnant Women. The Journal of Sexual Medicine, 11, 146-153. https://doi.org/10.1111/jsm.12347

[16] Ferreira, D.Q., Nakamura, M.U., de Souza, E., Mariani Neto, C., Ribeiro, M.C., et al. (2012) Sexual Function and Quality of Life of Low-Risk Pregnant Women. Revista Brasileira de Ginecologia e Obstetrícia, 34, 409-413. https://doi.org/10.1590/S0100-72032012000900004

[17] Ribeiro, M.C., Nakamura, M.U., Abdo, C.H.N., Torloni, M.R., et al. (2011) Pregnancy and Gestational Diabetes: A Prejudicial Combination to Female Sexual Function? Revista Brasileira de Ginecologia e Obstetrícia, 33, 219-224.

[18] Souza, F.D.O., Dias, L.A.R., Franco, M.D.M., Guirro, E.C.D.O., Cavalli, R.D.C., Lara, L.A.D.S., et al. (2013) Assessment of Female Sexual Function in Pregnant Women with Gestational Diabetes Mellitus. The Journal of Sexual Medicine, 10, 1350-1354. https://doi.org/10.1111/jsm.12106

[19] Johnson, C.E. (2011) Sexual Health during Pregnancy and the Postpartum. The Journal of Sexual Medicine, 8, 1267-1284. https://doi.org/10.1111/j.1743-6109.2011.02223.x

[20] Hanafy, S., Srour, N.E. and Mostafa, T. (2014) Female Sexual Dysfunction across the Three Pregnancy Trimesters: An Egyptian Study. Sex Health, 11, 240-243. https://doi.org/10.1071/SH13153

[21] Naldoni, L.M.V., Pazmiño, M.A.V., Pezzan, P.A.O., Pereira, S.B., Duarte, G. and Ferreira, C.H.J. (2011) Evaluation of Sexual Function in Brazilian Pregnant Women. Journal of Sex \& Marital Therapy, 37, 116-129. https://doi.org/10.1080/0092623X.2011.560537

[22] Alsibiani, S.A. (2014) Effects of Pregnancy on Sexual Function: Findings from a Survey of Saudi Women. Saudi Medical Journal, 35, 482-487.

[23] Corbacioglu, A., Bakir, V.L., Akbayir, O., Cilesiz Goksedef, B.P. and Akca, A. (2012) 
The Role of Pregnancy Awareness on Female Sexual Function in Early Gestation. The Journal of Sexual Medicine, 9, 1897-1903. https://doi.org/10.1111/j.1743-6109.2012.02740.x

[24] Bezerra, I.F.D., de Sousa, V.P.S., dos Santos, L.C. and Viana, E de, S.R. (2015) Comparação da qualidade de vida em gestantes com disfunção sexual. Revista Brasileira de Ginecologia e Obstetrícia, 37, 266-271. https://doi.org/10.1590/SO100-720320150005254

[25] Aslan, G., Aslan, D., Kizılyar, A., Spahi, C.I. and Esen, A. (2005) A Prospective Analysis of Sexual Functions during Pregnancy. International Journal of Impotence Research, 17, 154-157. https://doi.org/10.1038/sj.ijir.3901288

[26] Abouzari-Gazafroodi, K., Najafi, F., Kazemnejad, E., Rahnama, P. and Montazeri, A. (2015) Demographic and Obstetric Factors Affecting Women's Sexual Functioning during Pregnancy. Reproductive Health, 12, 72. https://doi.org/10.1186/s12978-015-0065-0

[27] Oniye, A.O., Yahaya, L.A., Esere, M.O. and Ogunsanmi, J.O. (2008) Marriage, Sex and Family Counselling. Unilorin Press, Ilorin, 25-62.

[28] Malarewicz, A., Szymkiewicz, J. and Rogala, J. (2006). Sexuality of Pregnant Women. Ginekologia Polska, 77, 733-739.

[29] Corbacioglu Esmer, A., Akca, A., Akbayir, O., Goksedef, B.P.C. and Bakir, V.L. (2013) Female Sexual Function and Associated Factors during Pregnancy. Journal of Obstetrics and Gynaecology Research, 39, 1165-1172. https://doi.org/10.1111/jog.12048

[30] Pauleta, J.R., Pereira, N.M. and Graça, L.M. (2010) Sexuality during Pregnancy. The Journal of Sexual Medicine, 7, 136-142. https://doi.org/10.1111/j.1743-6109.2009.01538.x

[31] Laumann, E.O., Gagnon, J.H., Michael, R.T. and Michaels, S. (1994) The Social Organization of Sexuality: Sexual Practices in the United States. University of Chicago Press, Chicago, IL.

[32] Yildiz, H. (2015) The Relation between Prepregnancy Sexuality and Sexual Function during Pregnancy and the Postpartum Period: A Prospective Study. Journal of Sex \& Marital Therapy, 41, 49-59. https://doi.org/10.1080/0092623X.2013.811452

[33] Serati, M., Salvatore, S., Siesto, G., Cattoni, E., Zanirato, M., Khullar, V., Cromi, A., Ghezzi, F. and Bolis, P. (2010) Female Sexual Function during Pregnancy and after Childbirth. The Journal of Sexual Medicine, 7, 2782-2790. https://doi.org/10.1111/j.1743-6109.2010.01893.x

[34] Pauls, R.N., Occhino, J.A. and Dryfthout, V.L. (2008) Effects of Pregnancy on Female Sexual Function and Body Image: A Prospective Study. The Journal of Sexual Medicine, 5, 1915-1922. https://doi.org/10.1111/j.1743-6109.2008.00884.x

[35] Erol, B., Sanli, O., Korkmaz, D., Seyhan, A., Akman, T. and Kardioglu, A. (2007) A Cross-Sectional Study of Female Sexual Function and Dysfunction during Pregnancy. The Journal of Sexual Medicine, 4, 1381-1387. https://doi.org/10.1111/j.1743-6109.2007.00559.x

[36] Sossa, L. (2014) Sexual Behavior during Pregnancy: A Descriptive Correlational Study among Women. European Journal of Medical Research, 2, 16-27.

[37] Saotome, T.T., Yonezawa, K. and Suganuma, N. (2018) Sexual Dysfunction and Satisfaction in Japanese Couples During Pregnancy and Postpartum. The Journal of Sexual Medicine, 6, 348-355. https://doi.org/10.1016/j.esxm.2018.08.003

[38] Varnier, S.A. and Rosen, N.O. (2017) Sexual Distress and Sexual Problems during 
Pregnancy: Associations with Sexual and Relationship Satisfaction. The Journal of Sexual Medicine, 14, 387-395. https://doi.org/10.1016/j.jsxm.2016.12.239

[39] Seven, M., Akyüz, A. and Güngör, S. (2015) Predictors of Sexual Function during Pregnancy. Journal of Obstetrics and Gynaecology, 35, 691-695.

https://doi.org/10.3109/01443615.2015.1006596 